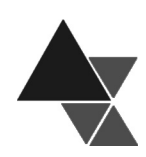

\title{
Conselhos de Alimentação Escolar (CAEs): análise dos pareceres conclusivos sobre a execução do Programa Nacional de Alimentação Escolar (PNAE) ${ }^{1}$
}

\author{
Marina Vieira da Silva ${ }^{2}$ e Mariana Schievano Danelon ${ }^{3}$
}

Os Conselhos de Alimentação Escolar (CAEs) são órgãos deliberativos que devem, entre as suas competências, elaborar um parecer conclusivo quanto à regularidade da aplicação, pelos Estados e Municípios, dos recursos destinados à alimentação escolar. A análise destes pareceres pode fornecer subsídios para a avaliação do Programa Nacional de Alimentação Escolar (PNAE). O objetivo deste trabalho foi analisar as informações contidas nos pareceres elaborados, no ano de 2003, pelos CAEs de amostra de Municípios $(n=568)$ da totalidade das Regiões geográficas do Brasil. Os resultados mostraram que em 8,5\% dos Municípios (sendo que destes, 89,3\% pertenciam às Regiões Norte e Nordeste) não houve o fornecimento de refeições em um mínimo de 200 dias letivos, conforme preconizado em legislação. O custo médio da refeição foi de $\mathrm{R} \$ 0,22$, e na maioria dos Municípios o custo excedeu o valor repassado pelo Governo Federal, indicando a complementação de recursos pelos Estados e Municípios. A insuficiência dos recursos federais destinados ao programa foi a principal crítica realizada pelos conselheiros nos pareceres. Entre os elogios, predominaram a qualidade da alimentação oferecida pelo programa, o fato desta ser bem aceita pelos alunos e a presença do nutricionista. Parcela dos conselheiros deixou de informar aspectos que deveriam constar no parecer, o que pode indicar desconhecimento acerca do preenchimento dos documentos ou da rotina de execução do programa. Conclui-se que os pareceres contêm informações relevantes para a melhoria do PNAE e que esforços devem ser dedicados na capacitação dos conselheiros para a elaboração dos mesmos.

Palavras-chave: Alimentação escolar. Conselho de Alimentação Escolar. Política pública. Programa social.

\section{Brazilian School Food Councils (CAEs): analysis of the conclusive reports related to the implementation of the Brazilian School Feeding Program}

Brazilian School Food Councils (CAEs) are deliberative councils that must, among their scope, develop a conclusive report about the implementation regularity of resources for school feeding by States and Municipalities. The analysis of these reports may subsidy the evaluation of the Brazilian School Feeding Program (PNAE). The aim of this study was to analyze the information contained in the conclusive reports prepared in the year of 2003 by CAE sample of municipalities $(n=568)$ of the totality of the geographic Regions of Brazil. The results showed that in $8.5 \%$ of the municipalities (and of these, $89.3 \%$ belonged to the North and Northeast) there was no provision of meals in a minimum of 200 school days, as prescribed in legislation. The average cost of the school meal was US $\$ 0.08$, and in most municipalities the cost exceeded the value transferred by the Federal Government, which indicates that States and Municipalities had also to invest own funds in the program. The insufficiency of federal resources for the program was the main criticism made by the council members. Among the compliments, the quality of the food offered by the program, the fact that it is well accepted by the students and the presence of a nutritionist prevailed. A portion of council members failed to inform aspects that should be included in the conclusive report, which may indicate lack of

\footnotetext{
${ }^{1}$ Pesquisa financiada pelo Conselho Nacional de Desenvolvimento Científico e Tecnológico - CNPq (Processo 504369/2003-2).

2 Prof ${ }^{a}$ Drª do Departamento de Agroindústria, Alimentos e Nutrição da Escola Superior de Agricultura “Luiz de Queiroz” (ESALQ), Universidade de São Paulo (USP). Correspondência: Av. Pádua Dias, 11, Piracicaba, SP. CEP: 13418-900. Tel. (19) 3429-4150. E-mail: marinavieiradasilva@usp.br.

${ }^{3}$ Doutora em Alimentos e Nutrição pela Faculdade de Engenharia de Alimentos (FEA), Universidade Estadual de Campinas (UNICAMP). Mestre em Ciência e Tecnologia de Alimentos pela ESALQ/USP.
} 
understanding about the completion of the documents or about the routine of the program implementation. It was concluded that the conclusive reports contain relevant information for the improvement of PNAE and that efforts should be dedicated in training the council members for the preparation of these documents.

Key-words: School feeding. School Food Council. Public policy. Social program.

\section{INTRODUÇÃO}

O Programa Nacional de Alimentação Escolar (PNAE), um dos mais antigos e abrangentes programas de suplementação alimentar em vigor no Brasil, passou por expressivas mudanças a partir de 12 de julho de 1994, com a Lei № 8.913 [1], na qual foi regulamentada a sua descentralização. Nesta legislação estava previsto que os recursos destinados ao programa, diretamente proporcionais ao número de alunos matriculados em unidades de educação pré-escolar e de ensino fundamental, seriam repassados em parcelas mensais aos Estados, ao Distrito Federal (DF) e aos Municípios que tivessem em funcionamento o Conselho de Alimentação Escolar (CAE). Este Conselho deveria ser composto por representantes da comunidade escolar e de outros segmentos da sociedade local e, entre as suas atribuições, previa-se a fiscalização e o controle da aplicação dos recursos destinados à merenda escolar. Os Estados e Municípios teriam a responsabilidade de elaboração de cardápios por nutricionista capacitado e com a colaboração do Conselho. Trata-se de iniciativa que representou um substancial avanço para a universalização do PNAE e que inovou ao garantir a participação da comunidade na gestão do programa.

Os CAE municipais foram então criados por exigência dos governos estaduais e federal para viabilizarem a celebração dos convênios de descentralização do PNAE. Em 1998, o PNAE passou a ser administrado pelo Fundo Nacional de Desenvolvimento da Educação (FNDE). A descentralização foi assegurada pela Medida Provisória (MP) № 1.784, de 14 de dezembro de 1998, sob o comando do FNDE, que proveu o repasse direto e automático dos recursos financeiros aos Municípios e secretarias de educação, sem a necessidade prévia da celebração de convênios, o que imprimiu agilidade e facilidade ao processo [2]. Os Estados, Municípios ou DF deixaram de ser identificados como "convenentes" e passaram a ser Entidades Executoras, responsáveis pelo recebimento dos recursos transferidos pelo FNDE e pela execução do PNAE.
Tanto a composição quanto as atribuições do CAE foram alteradas e ampliadas por legislações posteriores, como as MP № 1.979, de 02 de junho de 2000 e № 2.178-36, de 24 de agosto de 2001; as Resoluções № 35, de 01 de setembro de 2005, № 001, de 26 de janeiro de 2005, № 38, de 23 de agosto de 2004 e № 38, de 16 de julho de 2009; e a Portaria № 251, de 03 de março de 2000 [3]. Como resultado destes imperativos legais, o CAE é definido como um órgão deliberativo, fiscalizador e de assessoramento, que deve ser instituído na totalidade dos Municípios brasileiros e ser composto por sete membros, a saber: um representante indicado pelo poder executivo, dois representantes dos professores, dois representantes dos pais de alunos e dois representantes da sociedade civil. Se a entidade executora tiver mais de cem unidades de ensino básico, a composição do CAE poderá aumentar, segundo a proporção preconizada na legislação [4].

Entre as competências do CAE estão: a) acompanhar e fiscalizar a aplicação dos recursos destinados à alimentação escolar; b) zelar pela qualidade dos produtos, desde a compra até a distribuição aos alunos, observando sempre as boas práticas higiênicas e sanitárias; c) acompanhar se os cardápios estão sendo cumpridos e se são aceitos pelos alunos; d) participar das licitações e chamadas públicas; e) receber e analisar a prestação de contas do PNAE (enviada pela entidade executora) e remeter ao FNDE o Demonstrativo Sintético Anual da Execução Físico-Financeira com parecer conclusivo sobre a regularidade da prestação de contas; f) comunicar qualquer irregularidade identificada na execução do PNAE ao FNDE, à Controladoria Geral da União, ao Ministério Público e ao Tribunal de Contas da União [4].

Em 2005 foi publicado o "Manual de Gestão Eficiente da Merenda Escolar", que reuniu orientações aos membros do CAE, sistematizando os principais aspectos que devem ser verificados na execução do programa, como por exemplo: a garantia de que o dinheiro foi realmente gasto com alimentos para a merenda, se os produtos comprados foram efetivamente usados no preparo da alimentação escolar 
e se os preços pagos estão de acordo com os praticados pelo mercado. Nas visitas às unidades de ensino é importante observar se a merenda é servida de forma regular, se os alimentos reúnem atributos que garantam a sua qualidade e se é respeitada a data de validade, se as refeições coincidem com as apresentadas nos cardápios e se a escola possui boas condições de armazenamento dos produtos que recebe. A opinião dos pais deve ser considerada quanto à regularidade do serviço de merenda na escola, à aceitação das refeições pelos estudantes, entre outros aspectos. $\mathrm{Na}$ elaboração do parecer conclusivo pelos membros do CAE, deve ser relatada a ocorrência de qualquer irregularidade na operacionalização do programa [5]. Além destas orientações, roteiros, contendo instruções para a elaboração do parecer conclusivo e para o preenchimento do Demonstrativo Sintético Anual da Execução Físico-Financeira do PNAE, constam na Resolução № 38, de 16 de julho de 2009, em vigor no país [4].

Apesar das várias competências e atividades previstas para os conselhos, os primeiros trabalhos de pesquisa subsequentes à descentralização do PNAE mostraram que os CAEs apresentavam desempenho bem aquém do previsto [6-10]. Em amostra de Municípios catarinenses $(n=152)$, verificou-se que a maioria dos CAEs desempenhava atribuições, tais como a análise da prestação de contas, a fiscalização dos recursos, o zelo pela qualidade do PNAE, orientações quanto ao armazenamento dos alimentos, a participação na elaboração do cardápio e o acompanhamento da compra de gêneros; entretanto, apenas 22,4\% realizavam todas as atribuições com frequência maior ou igual à anual [11]. Belik \& Chaim [12], avaliando o perfil de gestão do PNAE nos Municípios inscritos para o prêmio Gestor Eficiente da Merenda Escolar, nos anos de 2004 e 2005, consideraram a atuação dos membros do CAE (avaliada pelo número de reuniões por ano) apenas como razoável. Os autores destacaram, no entanto, que em alguns Municípios o CAE foi determinante para redirecionar a gestão do PNAE, influenciando na decisão quanto à adoção da terceirização da alimentação escolar, exigindo a contratação de nutricionistas para atender ao programa, participando nos processos de licitação, ou acompanhando a aceitação do cardápio pelos alunos.

Não sobram dúvidas de que os CAEs devem ser atuantes e exercer papel importante quanto ao acompanhamento e fiscalização do programa. De acordo com Pipitone et al. [8], os CAEs necessitam aprimorar o seu desempenho porque da efetiva e autônoma atuação de seus conselheiros depende o bom funcionamento do PNAE.

Nota-se, também, que os pareceres do CAE, elaborados anualmente, podem conter informações valiosas acerca da execução do programa. A avaliação, de forma sistemática, destes pareceres pode ser ferramenta importante na análise do desempenho do PNAE, bem como na identificação de possíveis correções e melhorias [13]. No entanto, ainda são escassas as análises publicadas acerca destes documentos.

Face ao exposto, o objetivo do presente trabalho foi analisar as informações contidas nos pareceres elaborados, no ano de 2003, pelos CAE de amostra de Municípios do país, avaliando o perfil de atendimento do PNAE nestes Municípios, bem como as críticas, sugestões e elogios conferidos pelos conselheiros à operacionalização do programa.

\section{METODOLOGIA}

Este trabalho integra o projeto intitulado "Contrastes regionais nos custos, qualidade e operacionalização do Programa Nacional de Alimentação Escolar (PNAE) e seu impacto sobre os padrões alimentares da população brasileira", realizado com o apoio financeiro do Conselho Nacional de Desenvolvimento Científico e Tecnológico (CNPq), Processo 504369/2003-2.

Com base nos dados do Censo Escolar de 2004 [14], foi realizada uma hierarquização da totalidade dos Municípios (do menor para o maior, segundo o número de alunos, com idade entre seis e catorze anos, matriculados na rede pública de ensino). Os Municípios foram então classificados de acordo com a População escolar (Popesc) e os intervalos do Índice de Desenvolvimento Humano Municipal (IDHM) [15], conforme descrição mostrada a seguir:

1) Estrato 1: $0 \leq \mathrm{IDHM} \leq 0,60$ e Popesc $\leq 2.000$ alunos

2) Estrato 1.2: $0 \leq \mathrm{IDHM} \leq 0,60$ e $2.000 \leq$ Popesc $\leq$ 10.000 alunos

3) Estrato 1.3: $0 \leq \mathrm{IDHM} \leq 0,60$ e Popesc $>10.000$ alunos 
4) Estrato 2.1: 0,6 < IDHM $\leq 0,75$ e Popesc $\leq 2.000$ alunos

5) Estrato 2.2: $0<\mathrm{IDHM} \leq 0,75$ e $2.000<$ Popesc) $\leq$ 10.000 alunos

6) Estrato 2.3: 0,60 < IDHM $<0,75$ e Popesc $>10.000$ alunos

7) Estrato 3.1: IDHM $>0,75$ e Popesc $\leq 2.000$ alunos

8) Estrato 3.2: IDHM $>0,75$ e $2000<$ Popesc $\leq$ 10.000 alunos

9) Estrato 3.3: IDHM $>0,75$ e Popesc $>10.000$ alunos

Por meio de software especificamente elaborado para a pesquisa, foram sorteados, em cada estrato descrito anteriormente, os Municípios que deveriam integrar a amostra. $\mathrm{O}$ sorteio foi finalizado quando a amostra contemplou 10\% da totalidade dos Municípios do país.

Foram solicitadas, junto ao FNDE, cópias dos relatórios elaborados pelos CAEs dos Municípios que integraram a amostra do presente estudo $(n=568)$. Após o estabelecimento de inúmeros contatos, foram disponibilizadas, por correio, pelo FNDE as cópias dos relatórios (contendo o Demonstrativo Sintético Anual da Execução Físico-Financeira e o parecer conclusivo do CAE), do ano de 2003, aprovados pelo Tribunal de Contas da União.

As informações dos relatórios foram compiladas em banco de dados utilizando-se o programa Exce ${ }^{\circledR}$. Neste trabalho, foram analisadas as questões contidas nos pareceres referentes ao número de alunos atendidos pelo PNAE em cada Município, número de refeições servidas, dias de atendimento do programa, custo médio per capita da refeição, recursos totais gastos com o programa e recursos gastos com gêneros alimentícios. Analisaram-se, também, as críticas, as sugestões e os elogios elaborados pelos conselheiros. Análises descritivas (média e frequências) e testes de qui-quadrado foram calculados com auxilio do software Statistical Analysis System (SAS), versão 8.2 [16], empregando-se nível de significância de 5\%.

\section{RESULTADOS}

Conforme observado na Tabela 1, 568 Municípios compuseram a amostra, sendo a maior proporção pertencente aos Estados da Região Norte $(46,8 \%)$, seguidos pelos do Sudeste $(27,8 \%)$, Nordeste $(24,3 \%)$, Sul $(0,7 \%)$ e Centro-oeste $(0,4 \%)$.

A maior parcela $(27,1 \%)$ dos Municípios registrou o atendimento diário, pelo PNAE, de um número total de escolares no intervalo compreendido entre 1001 e 2500 . Também é interessante observar que $23,4 \%$ dos Municípios amostrados atendiam diariamente, por meio do programa, pelo menos 5.001 alunos. Ao se analisar as modalidades de ensino, em 28,6\% dos Municípios eram atendidos diariamente entre 101 e 250 pré-escolares. Para o ensino fundamental, predominou o atendimento de no máximo 2.500 alunos. A maior parcela $(78,2 \%)$ dos Municípios da amostra atendia, por dia, no máximo 50 alunos matriculados em entidades filantrópicas (Tabela 2).

$\mathrm{Na}$ maioria dos Municípios (86,4\%) a alimentação escolar foi distribuída em 200 dias letivos. Menor proporção $(5,1 \%)$ revelou o oferecimento em no mínimo 201 dias. De forma contrária, 8,5\% dos Municípios registraram número de dias de atendimento pelo programa inferior a 200. As diferenças quanto aos dias de atendimento do PNAE, de acordo com as Regiões do país, foram estatisticamente significativas, pelo teste de qui-quadrado $\quad\left(\chi^{2}=18,19\right.$, com 6 graus de liberdade, $p=0,0058)$ : entre os Municípios cujo programa não atendia 200 dias letivos, a maior proporção pertencia às Regiões Norte $(67,9 \%)$ e Nordeste $(21,4 \%)$.

Entre os Municípios integrantes da presente pesquisa o número total de refeições distribuídas pelo PNAE diariamente foi de 361.731 .045 (mediana $=$ 356.800). A maior proporção (43,7\%) de Municípios forneceu, por meio do PNAE, números que variaram entre 100.001 e 500.000 refeições diárias (Tabela 3).

Considerando os Municípios para os quais se dispunha de informações válidas quanto ao montante de recursos destinados ao PNAE $(n=329)$, a receita total dedicada ao programa foi de $\mathrm{R} \$ 45.466 .713,95$ (mediana $=\mathrm{R} \$ 45.578,00$ ). Examinando a distribuição dos Municípios de acordo com os intervalos de recursos totais gastos (Tabela 4), nota-se que expressiva parcela $(37,7 \%)$ apresentou gastos de no máximo $\mathrm{R} \$$ $30.000,00$. Em situação oposta, reduzida proporção $(4,0 \%)$ contava com valores superiores a $R \$$ 
500.000,00. Analisando os gastos com a aquisição de gêneros alimentícios reduzida parcela (3,6\%) de integrantes da pesquisa destinava valores acima de $\mathrm{R} \$$ $500.000,00$, enquanto que praticamente $1 / 3$ da amostra dispunha de valores entre $\mathrm{R} \$ 100.000,01$ e $\mathrm{R} \$$ $500.000,00$ para a referida finalidade.

O custo médio per capita da refeição servida pelo PNAE (considerando apenas gastos com gêneros alimentícios) foi de $\mathrm{R} \$ 0,22$. Em 28,3\% dos casos o custo correspondeu ao valor repassado pelo FNDE para alunos matriculados no ensino fundamental e préescolas, em 2003: R\$ 0,13. A maior parcela dos Municípios (59,5\%), no entanto, registrou custos superiores ao repasse federal. Analisando a distribuição segundo as Regiões, no Nordeste a maioria dos Municípios (69,0\%) utilizava no máximo os $\mathrm{R} \$ 0,13$ para cada refeição; já no Sudeste o custo superava o valor destinado pelo FNDE em 82,0\% dos Municípios (Tabela 5).

Tabela 1. Distribuição dos Municípios que integram a amostra de acordo com a Região e o Estado de origem. Brasil, 2005

\begin{tabular}{|c|c|c|c|}
\hline Região & Estado & № de Municípios & Participação na amostra (\%) \\
\hline \multirow[t]{7}{*}{ Norte } & Tocantins & 104 & 18,31 \\
\hline & Pará & 63 & 11,09 \\
\hline & Amazonas & 39 & 6,87 \\
\hline & Rondônia & 28 & 4,93 \\
\hline & Acre & 13 & 2,29 \\
\hline & Roraima & 11 & 1,94 \\
\hline & Amapá & 8 & 1,41 \\
\hline \multirow[t]{4}{*}{ Sudeste } & São Paulo & 91 & 16,02 \\
\hline & Minas Gerais & 58 & 10,21 \\
\hline & Rio de Janeiro & 6 & 1,06 \\
\hline & Espírito Santo & 3 & 0,53 \\
\hline \multirow[t]{9}{*}{ Nordeste } & Maranhão & 28 & 4,93 \\
\hline & Paraíba & 23 & 4,05 \\
\hline & Piauí & 22 & 3,87 \\
\hline & Bahia & 22 & 3,87 \\
\hline & Pernambuco & 16 & 2,82 \\
\hline & Ceará & 12 & 2,11 \\
\hline & Rio Grande do Norte & 7 & 1,23 \\
\hline & Alagoas & 6 & 1,06 \\
\hline & Sergipe & 2 & 0,35 \\
\hline \multirow[t]{3}{*}{ Sul } & Santa Catarina & 2 & 0,35 \\
\hline & Rio Grande do Sul & 1 & 0,18 \\
\hline & Paraná & 1 & 0,18 \\
\hline Centro-Oeste & Goiás & 2 & 0,35 \\
\hline Total & & 568 & 100,00 \\
\hline
\end{tabular}


Tabela 2. Distribuição dos Municípios integrantes da amostra, de acordo com o número (total e segundo as categorias pré-escola, ensino fundamental e entidades filantrópicas) de alunos atendidos diariamente pelo Programa Nacional de Alimentação Escolar (PNAE), em 2003

\begin{tabular}{|c|c|c|}
\hline Número de alunos atendidos pelo Programa & Número de Municípios & Frequência $(\%)$ \\
\hline \multicolumn{3}{|l|}{ Pré-escola* } \\
\hline Até 100 & 62 & 18,8 \\
\hline 101 a 250 & 94 & 28,6 \\
\hline 251 a 500 & 64 & 19,5 \\
\hline 501 a 1.000 & 56 & 17,0 \\
\hline 1.001 a 2.500 & 42 & 12,8 \\
\hline Acima de 2.500 & 11 & 3,3 \\
\hline \multicolumn{3}{|l|}{ Ensino fundamental** } \\
\hline Até 500 & 56 & 17,0 \\
\hline 501 a 1.000 & 74 & 22,4 \\
\hline 1.001 a 2.500 & 82 & 24,8 \\
\hline 2.501 a 5.000 & 52 & 15,8 \\
\hline 5.001 a 10.000 & 37 & 11,2 \\
\hline Acima de 10.000 & 29 & 8,8 \\
\hline \multicolumn{3}{|l|}{ Entidades filantrópicas** } \\
\hline Até 50 & 258 & 78,2 \\
\hline 51 a 100 & 24 & 7,3 \\
\hline 101 a 250 & 26 & 7,9 \\
\hline 251 a 1.000 & 16 & 4,8 \\
\hline Acima de 1.000 & 6 & 1,8 \\
\hline \multicolumn{3}{|l|}{ Total* } \\
\hline Até 100 & 6 & 1,8 \\
\hline 101 a 500 & 30 & 9,1 \\
\hline 501 a 1.000 & 73 & 22,2 \\
\hline 1.001 a 2.500 & 89 & 27,1 \\
\hline 2.501 a 5.000 & 54 & 16,4 \\
\hline Acima de 5.000 & 77 & 23,4 \\
\hline
\end{tabular}

Notas: * Informações disponíveis para 329 Municípios; ** Informações disponíveis para 330 Municípios. 
Tabela 3. Distribuição dos Municípios integrantes da amostra, de acordo com o número de refeições distribuídas diariamente, em 2003

\begin{tabular}{lrr}
\hline \multicolumn{1}{c}{ Número de refeições } & \multicolumn{2}{c}{ Municípios } \\
\cline { 2 - 4 } & \multicolumn{1}{c}{$\boldsymbol{n}$} & \% \\
\hline Até 10.000 & 13 & 11,2 \\
10.001 a 100.000 & 37 & 43,7 \\
100.001 a 500.000 & 144 & 17,3 \\
500.001 a 1.000 .000 & 57 & 21,2 \\
1.000 .001 a 5.000.000 & 70 & 2,7 \\
Acima de 5.000.000 & 9 & 100,00 \\
\hline Total & 330 & \\
\hline
\end{tabular}

Nota: Informações disponíveis para 330 Municípios.

Tabela 4. Distribuição dos Municípios integrantes da amostra, de acordo com intervalos de recursos (totais e parcela gasta com a aquisição de gêneros alimentícios) destinados ao PNAE, em 2003

\begin{tabular}{|c|c|c|}
\hline Recursos gastos (em Reais)* & Número de Municípios & Frequência (\%) \\
\hline \multicolumn{3}{|l|}{ Totais } \\
\hline Até 30.000,00 & 124 & 37,7 \\
\hline $30.000,01$ a $50.000,00$ & 52 & 15,8 \\
\hline $50.000,01$ a $100.000,00$ & 57 & 17,3 \\
\hline $100.000,01$ a $500.000,00$ & 83 & 25,2 \\
\hline Acima de 500.000,00 & 13 & 4,0 \\
\hline \multicolumn{3}{|l|}{ Com gêneros alimentícios** } \\
\hline Até 30.000,00 & 122 & 37,0 \\
\hline $30.000,01$ a $50.000,00$ & 55 & 16,7 \\
\hline $50.000,01$ a $100.000,00$ & 54 & 16,3 \\
\hline $100.000,01$ a $500.000,00$ & 87 & 26,4 \\
\hline Acima de 500.000,00 & 12 & 3,6 \\
\hline
\end{tabular}

Notas: * Informações disponíveis para 329 Municípios; ** Informações disponíveis para 330 Municípios.

Tabela 5. Distribuição dos Municípios integrantes da amostra, de acordo com o custo per capita diário (em Reais) da refeição, em 2003

\begin{tabular}{|c|c|c|c|c|c|c|c|c|c|c|}
\hline \multirow{3}{*}{$\begin{array}{l}\text { Custo da } \\
\text { refeição } \\
\text { (em Reais) }\end{array}$} & \multicolumn{8}{|c|}{ Distribuição dos Municípios por Região $^{1}$} & \multirow{2}{*}{\multicolumn{2}{|c|}{ Total }} \\
\hline & \multicolumn{2}{|c|}{ Norte } & \multicolumn{2}{|c|}{ Nordeste } & \multicolumn{2}{|c|}{ Sudeste } & \multicolumn{2}{|c|}{ Sul } & & \\
\hline & $n$ & $\%$ & $n$ & $\%$ & $n$ & $\%$ & $n$ & $\%$ & $n$ & $\%$ \\
\hline Até 0,12 & 21 & 14,6 & 6 & 10,4 & 12 & 10,3 & 0 & 0,0 & 39 & 12,2 \\
\hline 0,13 & 48 & 33,3 & 34 & 58,6 & 9 & 7,7 & 0 & 0,0 & 91 & 28,3 \\
\hline 0,14 a 0,30 & 65 & 45,1 & 17 & 29,3 & 50 & 42,7 & 1 & 50,0 & 133 & 41,4 \\
\hline 0,31 a 0,50 & 7 & 4,9 & 0 & 0,0 & 27 & 23,1 & 0 & 0,0 & 34 & 10,6 \\
\hline 0,51 a 0,80 & 3 & 2,1 & 1 & 1,7 & 15 & 12,8 & 0 & 0,0 & 19 & 5,9 \\
\hline Acima de 0,80 & 0 & 0,0 & 0 & 0,0 & 4 & 3,4 & 1 & 0,0 & 5 & 1,6 \\
\hline Total & 144 & 100,0 & 58 & 100,0 & 117 & 100,0 & 2 & 100,0 & 321 & 100,00 \\
\hline Valor médio & 0,17 & - & 0,14 & - & 0,32 & - & 0,57 & - & 0,22 & - \\
\hline Valor mínimo & 0,07 & - & 0,07 & - & 0,04 & - & 0,15 & - & 0,04 & - \\
\hline Valor máximo & 0,67 & - & 0,63 & - & 2,74 & - & 0,98 & - & 2,74 & - \\
\hline
\end{tabular}


A Tabela 6 reúne as citações identificadas nos relatórios referentes às críticas, sugestões e elogios elaborados pelos conselheiros dos CAEs, e separados segundo a Região de origem dos Municípios.

Quando se analisam as críticas ao PNAE, a maioria $(59,8 \%)$ das citações referiu-se à insuficiência dos recursos repassados pelo governo aos Municípios. Merecem destaque, também, as críticas à infraestratura do programa, no que se refere tanto à ausência de estrutura física para a aquisição e o armazenamento de gêneros, especialmente $\mathrm{o}$ acondicionamento dos perecíveis que demandam a utilização de freezers $(8,9 \%$ das citações), quanto à falta do profissional nutricionista (5,9\% das citações). O maior número de críticas foi reportado pelos conselheiros pertencentes à Região Norte. Nesta, além dos aspectos já mencionados, foram registradas, de forma mais frequente quando comparada as outras Regiões, dificuldades quanto à flutuação dos preços dos gêneros e aos sistemas de transporte para a entrega de alimentos às unidades de ensino.

O número de sugestões registradas nos pareceres foi pequeno, e houve predomínio das citações advindas da Região Norte $(58,3 \%)$ e das que sugerem que os recursos destinados ao PNAE sejam aumentados $(83,4 \%)$.

Quanto aos elogios identificados nos relatórios, o maior número de citações $(36,5 \%)$ fez referência à alimentação distribuída pelo PNAE ser considerada de boa qualidade ("variada e balanceada"). Os conselheiros valorizaram, também, o fato da alimentação escolar ser bem aceita pelos alunos $(27,3 \%$ das citações), o Município contar com a atuação do nutricionista $(14,4 \%)$ e o oferecimento sem interrupções da merenda escolar (10,6\%). Para os membros dos CAEs das Regiões Norte e Nordeste, a "redução da evasão escolar" também foi mencionada, de forma mais frequente, entre os elogios.

\section{DISCUSSÃO}

A análise dos pareceres dos membros dos CAEs permitiu identificar o perfil de atendimento do PNAE nos Municípios que integraram a amostra. Entre os indicadores que compuseram este perfil, merecem destaque o número de dias letivos nos quais a alimentação escolar foi oferecida aos alunos e o custo médio da refeição, que têm sido considerados como importantes aspectos na avaliação da eficácia e eficiência do PNAE [17,18].
No primeiro caso (dias de atendimento do programa), era esperada a distribuição das refeições em no mínimo 200 dias letivos, conforme preconizado pelo FNDE [4] na legislação que regulamenta o programa, situação que ocorreu na maioria dos Municípios pesquisados. No entanto, chama a atenção a parcela, pertencente principalmente às Regiões Norte e Nordeste, na qual a alimentação escolar deixou de ser oferecida em alguns dias do calendário letivo. Resultado semelhante já havia sido identificado em outros estudos [18,19]. Na pesquisa de Stolarski \& Castro [18], entre as justificativas para que a alimentação não fosse servida diariamente nas escolas do país foram mencionadas a falta de gêneros alimentícios e/ou de outros gêneros (gás e água), a ausência de manipuladores para o preparo e a escassez de recursos financeiros para a aquisição de gêneros.

No que se refere ao custo da refeição, no presente estudo, de forma semelhante ao que foi registrado por Belik \& Chaim [12], os valores extremos (menor e maior custo) gastos com a alimentação escolar não podem ser considerados como bons exemplos de gestão do programa. Nota-se que os Municípios que apresentaram o custo mínimo (com exceção dos da Região Sul) sequer gastaram o valor destinado pelo Governo Federal para a compra de gêneros. Já na situação oposta, o elevado valor gasto com a refeição (principalmente nas Regiões Sudeste e Sul) pode indicar uma má administração dos recursos.

Ainda com relação ao custo, os resultados evidenciaram que, de forma geral, na maioria dos Municípios há complementação dos recursos repassados pelo Governo Federal para o preparo e a distribuição das refeições. Essa realidade foi registrada também em outros trabalhos [7,12,13,18,20]. Estudo realizado por Belik \& Chaim [12] revelou que nos Municípios agraciados com o Prêmio Gestor Eficiente da Merenda Escolar, realizado pela Organização Não Governamental Ação Fome Zero, a execução do programa não era restrita ao uso do repasse do Governo Federal, havendo um esforço por parte dos Municípios para a complementação financeira, que alcançava, em média, mais de 100\% do valor repassado pelo FNDE.

Na presente pesquisa, por outro lado, chamou a atenção o fato de que na maioria dos Municípios da Região Nordeste (e também em expressiva parcela dos Municípios da Região Norte) o custo per capita da refeição correspondeu a no máximo o valor repassado pelo FNDE, ou seja, não foi reportada, pelos 
Tabela 6. Número e percentagem de citações relativas às críticas, sugestões e elogios registrados nos relatórios dos Conselhos de Alimentação Escolar (CAE), 2003 Total

Citações

Críticas
Recursos repassados pelo governo são insuficientes

Recursos repassados pelo governo são insuficientes
Ausência de estrutura para aquisição e armazenamento dos gêneros alimentícios (in natura ou não)

Município não possui nutricionista

Preços dos produtos adquiridos são elevados (preços inconstantes)

Sistema de transporte para entrega dos gêneros é ineficiente (falta de veículos e estradas ruins)

Atrasos na entrega dos gêneros pelos fornecedores

A merenda não é de boa qualidade

Falta fiscalização no armazenamento e data de validade dos produtos

Falta de documentos fiscais relativos aos alimentos comercializados pelos pequenos Norte

rodutores

Número insuficiente de merendeiras

\section{Total}

Sugestões

33

\%* $\begin{array}{ll}\text { Nordeste } \\ \text { \% }\end{array}$

33

56,9

$\% *$

n $\%$

\%* $n$

\%*
n $\%$ *

Necessidade de aumento dos recursos repassados pelo governo

Contratar nutricionistas

Oferecer cursos de capacitação, orientação, elaboração de cardápios aos conselheiros

Total

\section{Elogios}

Alimentação distribuída é de boa qualidade (variada, balanceada)

Boa aceitação pelos alunos

Município tem nutricionista

Eficiência no processo de distribuição da merenda (todos os dias, sem interrupção)

Redução da evasão escolar (alunos permanecem em sala de aula)

Armazenamento adequado dos alimentos

Merendeiras treinadas (manipulação adequada dos alimentos)

Melhoria da infraestrutura das cozinhas

O programa é uma alternativa de renda para pequenos produtores locais

Implantação do programa de educação alimentar

Convênio com universidades locais

$\begin{array}{rrrrrrrrrrr}4 & 6,9 & 1 & 10,0 & 4 & 11,8 & & & 9 & 8,9 \\ 3 & 5,2 & - & - & 3 & 8,8 & - & - & 6 & 5,9 \\ 5 & 8,6 & - & - & 1 & 3,0 & - & - & 6 & 5,9 \\ 4 & 6,9 & - & - & 1 & 3,0 & - & - & 5 & 4,9 \\ 3 & 5,2 & - & - & 1 & 2,9 & - & - & 4 & 3,9 \\ 2 & 3,5 & 2 & 20,0 & - & - & - & - & 4 & 3,9 \\ 2 & 3,4 & 1 & 10,0 & - & - & - & - & 3 & 2,9 \\ 2 & 3,4 & - & - & 1 & 2,9 & - & - & 3 & 2,9\end{array}$

$58 \quad 100,0$

100,0

$\begin{array}{rrrrrrrr}- & - & 1 & 2,9 & - & - & 1 & 1,0 \\ 10 & \mathbf{1 0 0 , 0} & \mathbf{3 4} & \mathbf{1 0 0 , 0} & - & - & \mathbf{1 0 2} & \mathbf{1 0 0 , 0}\end{array}$

Notas: * Percentagens calculadas em relação ao total observado na coluna segundo as catego não estavam disponíveis nos pareceres dos CAEs de Municípios da Região Centro-Oeste.

\begin{tabular}{rrrrrrrrrr}
6 & 85,7 & - & - & 2 & 66,7 & 2 & 100,0 & 10 & 83,4 \\
- & - & - & - & 1 & 33,3 & - & - & 1 & 8,3 \\
1 & 14,3 & - & - & - & - & - & - & 1 & 8,3 \\
\hline $\mathbf{7}$ & $\mathbf{1 0 0 , 0}$ & - & - & $\mathbf{3}$ & $\mathbf{1 0 0 , 0}$ & $\mathbf{2}$ & $\mathbf{1 0 0 , 0}$ & $\mathbf{1 2}$ & $\mathbf{1 0 0 , 0}$ \\
\hline & & & & & & & & & \\
68 & 41,2 & 12 & 26,1 & 53 & 35,1 & 1 & 20,0 & 134 & 36,5 \\
42 & 25,5 & 11 & 23,9 & 46 & 30,4 & 1 & 20,0 & 100 & 27,3 \\
24 & 14,6 & 6 & 13,0 & 23 & 15,2 & - & - & 53 & 14,4 \\
18 & 10,9 & 2 & 4,3 & 16 & 10,6 & 3 & 60,0 & 39 & 10,6 \\
6 & 3,6 & 10 & 21,7 & 1 & 0,7 & - & - & 17 & 4,6 \\
5 & 3,0 & 3 & 6,6 & 6 & 4,0 & - & - & 14 & 3,8 \\
1 & 0,6 & 2 & 4,4 & 2 & 1,3 & - & - & 5 & 1,4 \\
- & - & - & - & 2 & 1,3 & - & - & 2 & 0,5 \\
1 & 0,6 & - & - & - & - & - & - & 1 & 0,3 \\
- & - & - & - & 1 & 0,7 & - & - & 1 & 0,3 \\
- & - & - & - & 1 & 0,7 & - & - & 1 & 0,3 \\
$\mathbf{1 6 5}$ & $\mathbf{1 0 0 , 0}$ & $\mathbf{4 6}$ & $\mathbf{1 0 0 , 0}$ & $\mathbf{1 5 1}$ & $\mathbf{1 0 0 , 0}$ & $\mathbf{5}$ & $\mathbf{1 0 0 , 0}$ & $\mathbf{3 6 7}$ & $\mathbf{1 0 0 , 0}$ \\
\hline
\end{tabular}


conselheiros, uma complementação estadual e/ou municipal dos recursos federais. Embora na legislação que regulamenta o programa não seja estipulado um percentual de participação entre as esferas federal, estadual e municipal, é previsto que a obrigação de fornecer a alimentação escolar deva ser compartilhada entre as três esferas [3]. A não complementação dos recursos nas Regiões Norte e Nordeste pode ser uma das justificativas para o resultado observado na presente pesquisa, referente ao fato da alimentação escolar não ter sido distribuída na totalidade dos dias letivos naquelas Regiões: é possível que os recursos federais tenham sido insuficientes para a execução do programa, sem a contrapartida dos Estados e Municípios.

Independentemente da Região analisada, a insuficiência dos recursos repassados pelo Governo Federal foi justamente a principal crítica ao programa, feita pelos conselheiros. Trata-se de dificuldade já registrada em outros estudos [18,21-24]. É importante destacar que o valor per capita diário destinado pelo FNDE, para os pré-escolares, passou de R\$0,06 a R\$ 0,13 por dia em 2003 (ano ao qual se referem os pareceres analisados nesta pesquisa). Para alunos matriculados no ensino fundamental, os valores permaneceram fixos em $\mathrm{R} \$ 0,13$ por dia, por aluno, no período compreendido entre 1993 e 2003, só havendo aumento, para $\mathrm{R} \$ 0,15$, em 2004. Conforme registrado por Mafra \& Naves [22] e Ometto et al. [20], neste período de dez anos os preços dos alimentos sofreram reajustes, o que pode ter trazido dificuldades quanto à aquisição de alimentos e ao atendimento das metas do programa. Entre os resultados do presente estudo, nota-se, também, que a principal sugestão dos conselheiros foi justamente a necessidade de aumentar o valor repassado pelo Governo Federal. Vale registrar que desde 2004 o valor per capita destinado pela União ao programa tem aumentado, e atualmente totaliza $\mathrm{R} \$$ 0,30 para alunos de ensino fundamental e médio, R\$ 0,60 para os estudantes indígenas e quilombolas, $\mathrm{R} \$$ 0,50 para pré-escolares e $\mathrm{R} \$ 1,00$ para os matriculados em creches. Apesar da iniciativa do Governo Federal, os valores per capita atuais ainda podem ser considerados escassos para o atendimento das metas do programa.

Além da insuficiência de recursos financeiros, também foi criticada pelos conselheiros, na presente pesquisa, a infraestrutura do programa. Este resultado encontra concordância em outros estudos [18,25,26], nos quais foram registradas, entre as dificuldades para a execução do PNAE, a inadequação de equipamentos, de utensílios, da área física das cozinhas e de mobiliários, além da escassez de recursos humanos (tanto de merendeiras, envolvidas no preparo das refeições, quanto de nutricionistas, responsáveis pelo planejamento e supervisão do programa). No que se refere a este último aspecto, a ausência de nutricionistas, é importante destacar que apesar de estar previsto em legislação que o cardápio do PNAE deve ser elaborado por nutricionista habilitado, com a participação do CAE, dados do Conselho Federal de Nutricionistas revelaram que expressiva parcela dos Municípios ainda não contava com este profissional em 2005: dos 5564 Municípios atendidos pelo PNAE, 1830 possuíam nutricionistas cadastrados. Ainda de acordo com o referido Conselho, tem havido um aumento na participação deste profissional no programa, como resultado, entre outros fatores, da Resolução № 358, de 18 de maio de 2005, que definiu as atribuições técnicas do profissional no PNAE e estabeleceu parâmetro numérico de nutricionistas responsáveis técnicos que devem atuar no programa, calculado de acordo com o número de alunos e as modalidades de ensino presentes em cada Município. Entre 2005 e 2007, houve um aumento de 64\% no número de Municípios cujo PNAE contava com esse profissional $[27,28]$.

Ao se analisar os elogios conferidos pelos conselheiros ao programa, nota-se que a presença do nutricionista foi reconhecida entre as principais citações. Além deste fator, os conselheiros também valorizaram aspectos (como a qualidade da alimentação oferecida, a aceitação desta pelos alunos e a não interrupção da distribuição da merenda durante o calendário letivo) cuja avaliação pressupõe o acompanhamento constante dos membros do CAE no que se refere à rotina de execução do programa nas unidades escolares. É importante destacar que o acompanhamento do programa está entre as competências do CAE, e é encorajado que informações decorrentes deste acompanhamento (como a qualidade das refeições e a sua aceitação, por exemplo) sejam relatadas nos pareceres conclusivos [4]. A análise destes documentos no presente estudo, no entanto, revela que em apenas uma parcela dos pareceres foram mencionadas informações deste tipo, o que permite inferir que o acompanhamento do programa não era realizado em muitos Municípios, em 2003, ou que, se realizado, as informações não foram reportadas adequadamente pelos conselheiros nos pareceres. Em estudo realizado por Pipitone et al. [8], com base em informações obtidas entre 1997 e 1998 junto à amostra de 1378 Municípios brasileiros, foi verificado que em 
apenas 63,45\% dos Municípios o acompanhamento do programa, na escola, era realizado pelo CAE. Ainda de acordo com as autoras, uma atuação mais abrangente dos conselheiros, participando em todas as etapas do PNAE (programação, execução e avaliação), ocorreu em parcela ainda menor: 38,9\% dos Municípios.

Ainda com relação aos elogios mencionados no presente estudo, chamou a atenção as citações realizadas, principalmente pelos conselheiros da Região Nordeste, quanto à redução da evasão escolar. Um estudo realizado na Paraíba revelou que cerca de um quarto dos pais de alunos do ensino fundamental afirmaram que a alimentação escolar era fundamental para a permanência do filho na unidade de ensino [29]. É possível que em Regiões menos favorecidas economicamente, a alimentação escolar seja a principal refeição, ou a única do dia, para os estudantes, contribuindo para sanar a fome do dia e favorecendo a capacidade de concentração, a aprendizagem e o rendimento escolar, conforme já destacado por Abreu [30]. No entanto, é preciso ponderar que o PNAE não tem como objetivo principal a redução da evasão escolar e nem pode ser considerado como a solução para evitar o fracasso escolar, que são fenômenos de causas complexas [30,31]. Ao invés disso, é dever do Estado assegurar o acesso da população escolar à alimentação saudável e adequada, que cubra as necessidades nutricionais dos estudantes durante $\mathrm{O}$ período letivo, contribuindo para o crescimento biopsicossocial e a formação de bons hábitos alimentares ${ }^{[4]}$.

$\mathrm{Na}$ presente pesquisa, ao se analisar o conjunto de citações elaboradas pelos conselheiros nos pareceres, nota-se que o número de elogios foi maior que o de críticas e de sugestões, o que parece indicar, de forma geral, uma visão favorável dos membros do CAE no que se refere à execução do programa nos Municípios amostrados. No entanto, é importante destacar que apenas parcela dos CAEs, quando comparada à totalidade de Municípios integrantes da amostra, registrou comentários (críticas, elogios ou sugestões) nos pareceres. Além disso, em muitos documentos não constavam informações referentes ao perfil de atendimento do programa, tais como o número de alunos matriculados, o número de refeições servidas, $\mathrm{O}$ custo da refeição ou os recursos gastos com o programa. Essa situação pode demonstrar o desconhecimento dos membros do CAE acerca do preenchimento dos documentos ou acerca da rotina de execução do programa no Município.
A falta de conhecimento dos membros do CAE sobre a rotina do programa foi identificada em pesquisa anterior, realizada com 143 conselheiros, dos quais a maior proporção pertencia ao segmento que representava trabalhadores da educação, professores ou alunos. Entre os resultados daquela pesquisa, os conselheiros informaram que atividades como o procedimento licitatório e a análise de prestação de contas eram realizadas por eles com dificuldade, devido à presença de dúvidas. Para parcela dos conselheiros, o procedimento licitatório e a adequação do cardápio não eram realizados pelo conselho pela falta de conhecimento suficiente sobre os assuntos [32]. Em outro estudo, a maioria dos conselheiros de Município paulista declarou possuir poucas informações sobre a legislação que ampara o PNAE [33].

Gallina et al. [34] argumentam que o desconhecimento, evidenciado em diversos estudos, dos membros dos conselhos gestores de políticas públicas acerca, entre outros aspectos, das suas atribuições e das políticas específicas a que se dedicam, evidencia a falta de preparo dos conselheiros e dificulta a adoção das conquistas legais alcançadas. Segundo Paulo \& Medeiros [35], os CAEs são constituídos, em grande medida, por pessoas sem formação para o exercício da atividade e que não recebem treinamento adequado para que tenham condições de exercer o controle sobre o uso do recurso público. Os referidos autores destacaram que o FNDE fornece uma capacitação para os conselhos municipais, mas que esta focaliza os aspectos qualitativos da merenda, em detrimento dos procedimentos de controle fiscal, financeiro e licitatório. Ainda segundo os autores, uma auditoria realizada pelo Tribunal de Contas da União em 2002, junto a 67 prefeituras de 21 Estados, revelou que cerca de $60 \%$ dos conselheiros do CAE afirmaram não ter recebido qualquer tipo de capacitação por parte do FNDE.

Não sobram dúvidas de que a instituição dos CAEs nos Estados e Municípios representou um avanço para o programa, por garantir a participação da sociedade no acompanhamento e na fiscalização da rotina de execução do PNAE. Pela própria composição destes conselhos, preconizada para envolver diferentes setores da sociedade, é de se esperar que muitos membros não possuam conhecimento técnico necessário em todos os aspectos envolvidos na execução do programa (desde, por exemplo, o auxilio na elaboração de cardápios, até a análise de processos licitatórios ou a elaboração do parecer aprovando ou 
rejeitando a utilização dos recursos públicos). A capacitação dos membros do CAE torna-se, portanto, fundamental para que os conselheiros possam desempenhar as suas competências, assegurando o controle efetivo dos recursos investidos e o atendimento dos objetivos do programa. É interessante observar que entre as sugestões, conferidas pelos conselheiros no presente estudo, foi mencionada justamente a necessidade de oferecer cursos de capacitação e de orientação para os membros do CAE. Gallina et al. ${ }^{[34]}$ concluem que existe uma necessidade urgente de qualificação dos conselheiros, com vistas ao preparo conceitual e sociopolítico dos seus membros, e que, além da capacitação fundamentada em saberes formais, os debates devem incluir a reflexão sobre a realidade vivenciada nos conselhos, o que pode contribuir para o desenvolvimento de práticas mais participativas de controle social.

\section{CONCLUSÃO}

A análise dos pareceres conclusivos de amostra de conselhos de alimentação escolar do país revelou informações importantes para a avaliação e o aperfeiçoamento do PNAE. Foi possível identificar, entre outros aspectos, que em 2003 ainda havia Municípios (principalmente nas Regiões Norte e Nordeste) nos quais a alimentação escolar não era distribuída na totalidade dos dias letivos. Os resultados da pesquisa também não deixam dúvidas quanto à insatisfação dos conselhos, especialmente aqueles situados nas Regiões mais pobres do Brasil, com relação à verba repassada pela União para a compra de alimentos para a implementação do PNAE. Pôde ser constatado, por meio do custo médio per capita da alimentação escolar, que na maioria dos Municípios os recursos federais eram complementados pelos Estados e/ou Municípios.

O fato de parcela dos pareceres ter sido preenchida de forma incompleta permitiu inferir que os conselheiros não souberam responder algumas questões ou não fizeram o acompanhamento da rotina do PNAE no Município. Sugere-se que programas de capacitação para os conselheiros, envolvendo orientações desde a elaboração do cardápio, a aquisição de gêneros para o programa e a realização de testes de aceitabilidade até a análise da prestação de contas e a elaboração dos pareceres conclusivos, sejam realizados de forma periódica.
Destaca-se que os pareceres, quando elaborados adequadamente, contêm informações relevantes sobre o programa e sugere-se que a análise destes documentos, envolvendo não somente a aprovação ou a rejeição dos gastos com o programa, como também a avaliação dos indicadores de atendimento do PNAE, seja feita de forma contínua. Estudos envolvendo outras metodologias, como entrevistas junto aos membros do CAE, também podem complementar as informações acerca do programa.

Como limitação da pesquisa, os pareceres analisados no presente estudo referiram-se ao ano de 2003. É possível que o tempo decorrido desde a realização da pesquisa até os dias atuais tenha possibilitado uma maior experiência nos conselhos quanto à análise dos parâmetros do programa e à elaboração dos pareceres conclusivos. Além disso, informações relevantes, como aquelas relacionadas à aquisição de produtos da agricultura familiar e às formas de gestão do PNAE ainda não constavam no modelo do parecer daquele ano e, portanto, não foram objeto deste estudo. Apesar das limitações, dada a escassez de estudos na área, os resultados da presente pesquisa podem ser comparados e complementados pelas análises dos pareceres elaborados nos anos subsequentes.

\section{REFERÊNCIAS}

[1] Brasil. Lei № 8.913, de 12 de julho de 1994. Dispõe sobre a municipalização da merenda escolar. Diário Oficial da União, Brasília, 13 jul. 1994. Seção 1, p. 10522.

[2] Brasil. Medida Provisória № 1.784, de 14 de dezembro de 1998. Dispõe sobre o repasse de recursos financeiros do Programa Nacional de Alimentação Escolar, institui o Programa Dinheiro Direto na Escola, e dá outras providências. Diário Oficial da União, Brasília, 15 dez. 1998. Seção 1, p. 46.

[3] Fundo Nacional de Desenvolvimento da Educação (FNDE). Alimentação escolar [acesso em 08 dez 2012]. Disponível em:

http://www.fnde.gov.br/programas/alimentacaoescolar/alimentacao-escolar-apresentacao

[4] Brasil. Resolução № 38, de 16 de julho de 2009. Dispõe sobre o atendimento da alimentação escolar aos alunos da educação básica no Programa Nacional de Alimentação Escolar (PNAE). Diário Oficial da União, Brasilia, 08 dez. 2009. Seção 1, p. 10. 
[5] Apoio Fome Zero. Associação de apoio a políticas de segurança alimentar. Manual de Gestão Eficiente da Merenda Escolar. São Paulo; 2005.

[6] Instituto Nacional de Estudos e Pesquisas Educacionais. Síntese dos resultados da pesquisa avaliação da descentralização de recursos do FNDE e da merenda escolar. Brasilia: O Instituto; 1998.

[7] Pipitone MAP. Programa de Alimentação: um estudo sobre descentralização, escola e educadores [tese]. Campinas: Universidade Estadual de Campinas; 1997. 135 p.

[8] Pipitone MAP, Ometto AMH, Silva MV, Sturion GL, Furtuoso MCO, Oetterer M. Atuação dos Conselhos Municipais de Alimentação Escolar na gestão do Programa Nacional de Alimentação Escolar. Rev Nutr. 2003;16(2):15562.

[9] Santos L, Mazza RPD, Santos SMC, Santos LMP, Almeida DS, Almeida LC, et al. O papel do Conselho de Alimentação Escolar sob o enfoque da segurança alimentar. In: XVII Congresso Brasileiro de Ciência e Tecnologia de Alimentos, 2000, Fortaleza, Ceará. Anais... Fortaleza: SBCTA, 2000.

[10] Santos LMP, Santos SMC, Santana LAA, Henrique FCS, Mazza RPD, Santos LAS, et al. Avaliação de políticas públicas de segurança alimentar e combate à fome no período 1995 2002. 4 - Programa Nacional de Alimentação Escolar. Cad Saúde Pública. 2007;23(11):2681-93.

[11] Gabriel CG, Machado MS, Schmitz BAS, Corso ACT, Caldeiras GV, Vasconcelos FAG. Conselhos municipais de alimentação escolar em Santa Catarina: caracterização e perfil de atuação. Ciênc Saúde Colet. 2013;18(4): 971-78.

[12] Belik W, Chaim NA. O programa nacional de alimentação escolar e a gestão municipal: eficiência administrativa, controle social e desenvolvimento local. Rev Nutr. 2009;22(5):595-607.

[13] Bandeira LM, Chagas CMS, Gubert MB, Toral N, Monteiro RA. Análise dos pareceres conclusivos dos Conselhos de Alimentação Escolar sobre a execução do Programa Nacional de Alimentação Escolar. Rev Nutr. 2013;26(3):343-51.

[14] Instituto Nacional de Estudos e Pesquisas Educacionais. Censo Escolar 2004 [acesso em 10 maio 2006]. Disponível em: www.inep.gov.br

[15] Programa das Nações Unidas para o Desenvolvimento (PNUD). Atlas de Desenvolvimento Humano no Brasil.
2000 [acesso em 16 jan 2006]. Disponível em http://www.pnud.org.br

[16] SAS Institute Inc. The Statistical Analysis System (software). Version 8.2. Cary: SAS Institute Inc.; 2000.

[17] Almeida LMMC, Paulillo LF, Bergamasco SMPP, Ferrante VLSB. Políticas públicas, redes de segurança alimentar e agricultura familiar: elementos para construção de indicadores de eficácia. Estud Soc Agric. 2006;14(2):205-35.

[18] Stolarski MC, Castro D. Caminhos da alimentação escolar no Brasil: análise de uma política pública no período de 2003-2004. Revista Paranaense de Desenvolvimento. 2007;113:31-58

[19] Ministério da Educação. Instituto Nacional de Estudos e Pesquisas Educacionais (INEP). Avaliação do Programa Nacional de Alimentação Escolar (PNAE). Censo escolar 2004. Brasília: INEP; 2007.

[20] Ometto AMH, Sturion GL, Silva MV, Furtuoso MCO, Pipitone MAP. Programa nacional de alimentação escolar: principais componentes dos custos e seus determinantes. Nutrire. 2003;26:19-36.

[21] Carvalho DG. Licitações sustentáveis, alimentação escolar e desenvolvimento regional: uma discussão sobre o poder de compra governamental a favor da sustentabilidade. Planejamento e políticas públicas. 2009;32:115-47.

[22] Mafra LAS, Naves FL. Gestão de políticas sociais: a importância das articulações institucionais e setoriais em programas de segurança alimentar e nutricional. Cad EBAPE.BR. 2009;7(1):35-49.

[23] Mascarenhas JMO, Santos JC. Avaliação da composição nutricional dos cardápios e custos da alimentação escolar da rede municipal de Conceição do Jacuípe/BA. Sitientibus. 2006;35:75-90.

[24] Sturion GL. Programa de alimentação escolar: avaliação do desempenho em dez municípios brasileiros [tese]. Campinas: Universidade Estadual de Campinas; 2002. 269 p.

[25] Nogueira RM. O Programa Nacional de Alimentação Escolar como uma política pública: o caso de Campinas - SP [dissertação]. Campinas: Universidade Estadual de Campinas; 2004. 155 p.

[26] Vieira MNCM, Ferriani MGC, Gomes R, Santos GVB, Marchi EMM. Gestão de um programa de alimentação escolar em um município paulista. Seg Alim Nutr. 2008;15(1):29-48. 
[27] Conselho Federal de Nutricionistas. Resolução CFN № 358/2005. Dispõe sobre as atribuições do nutricionista no âmbito do Programa de Alimentação Escolar (PAE) e dá outras providências. Diário Oficial da União, Brasília, 22 jun. 2005. Seção 1, p. 139.

[28] Conselho Federal de Nutricionistas. 2012. O nutricionista no Programa de Alimentação Escolar [acesso em 10 dez 2012]. Disponível em: http://www.cfn.org.br/eficiente/ repositorio/Comunicacao/Material institucional/162.pdf

[29] Muniz VM, Carvalho AT. O Programa Nacional de Alimentação Escolar em município do estado da Paraíba: um estudo sob o olhar dos beneficiários do programa. Rev Nutr. 2007;20(3):285-96.

[30] Abreu M. Alimentação escolar: combate à desnutrição e ao fracasso escolar ou direito da criança e ato pedagógico? Em Aberto. 1995;15(67):5-20.
[31] Moysés MAA, Collares CAL. Aprofundando a discussão das relações entre desnutrição, fracasso escolar e merenda. Em Aberto. 1995;15(67):33-56.

[32] Bandeira LM, Recine E, Toral N. Dificuldades encontradas e prioridades para um curso de formação segundo integrantes de conselhos de alimentação escolar. Nutrire. 2011;36(Suppl.):233.

[33] Amistá MJM. Programa de alimentação escolar: perfil dos beneficiários, qualidade e atuação de gestores e da comunidade de Guariba [dissertação]. Piracicaba: Universidade de São Paulo; 2013. 173 p.

[34] Gallina LS, Teo CRPA, Munaro OS, Oliveira VSH. Representações sobre segurança alimentar e nutricional nos discursos de um conselho de alimentação escolar. Saúde Soc. 2012; 21(1):89-102.

[35] Paulo CVP, Medeiros HR. O controle social e o Tribunal de Contas da União: o caso dos conselhos de alimentação escolar. Revista do TCU. 2005;35(105). 